\title{
Mediterranean Diet Index (KIDMED) Adherence, Socioeconomic Determinants, and Nutritional Status of Portuguese Children: The Eat Mediterranean Program
}

\author{
Ana Isabel Rito a, b Ana Dinis ${ }^{c}$ Carla Rascôa ${ }^{c}$ António Maiac Sofia Mendes ${ }^{b}$ \\ Camila Stein-Novais ${ }^{c}$ João Limac \\ a Departamento de Alimentação e Nutrição, Instituto Nacional de Saúde Dr. Ricardo Jorge (INSA, IP), \\ Lisbon, Portugal; ${ }^{b}$ Centro de Estudos e Investigação em Dinâmicas Sociais e Saúde (CEIDSS), Oeiras, Portugal; \\ 'Administração Regional de Saúde de Lisboa e Vale do Tejo, I.P. (ARSLVT), Lisbon, Portugal
}

\section{Keywords}

Mediterranean diet $\cdot$ Public health $\cdot$ Dietary habits $\cdot$ KIDMED index $\cdot$ Socioeconomic determinants

\begin{abstract}
Background: Despite its health benefits, adherence to the Mediterranean diet (MD) has been decreasing, particularly in young generations and in Mediterranean regions, including Portugal. Socioeconomic and lifestyle factors have been shown to influence children and adolescents' eating habits. This study aimed to assess the association between socioeconomic factors and children's nutritional status with the MD adherence using the Eat Mediterranean (EM) program. Methods: Participant's BMI and adherence to the MD diet was assessed at baseline and after the intervention. Data regarding socioeconomic status and KIDMED Index were collected using a family record form. The intervention consisted of various educational sessions addressing the principles and promoting a Mediterranean dietary pattern in schools belonging to two municipalities in the central area of Portugal. A total of 1,772 participants (from preschool to secondary school) met the inclusion criteria for the study. Results: At the end of the program, the adherence to the MD diet improved significantly with participants increasing their ad-
\end{abstract}

herence to an optimal diet by $17.6 \%$. Daily intake of foods belonging to the MD diet also increased significantly, and the intake of high energy density foods decreased. Mother's educational level and household income were significantly $(p<0.0001)$ associated with optimal MD adherence by participants, in both stages. Nutritional status was not associated with the KIDMED Index. Discussion: The EM program showed to be effective in increasing MD adherence in this study population since optimal MD adherence was reported in most participants at the end of the EM program. Household income and mother's educational level were positively associated with the diet quality of the children and adolescents.

() 2019 The Author(s). Published by S. Karger AG, Basel on behalf of NOVA National School of Public Health

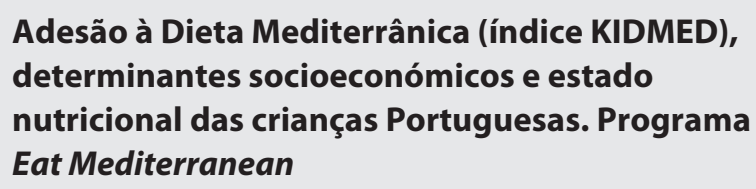

\section{KARGER}

E-Mail karger@karger.com www.karger.com/pjp

Karger Open access (c) 2019 The Author(s). Published by S. Karger AG, Basel on behalf of NOVA National School of Public Health

This article is licensed under the Creative Commons AttributionNonCommercial-NoDerivatives 4.0 International License (CC BYNC-ND) (http://www.karger.com/Services/OpenAccessLicense) Usage and distribution for commercial purposes as well as any distribution of modified material requires written permission.
Ana Isabel Rito

Instituto Nacional de Saúde Dr. Ricardo Jorge (INSA, IP)

Departamento de Alimentação e Nutrição

Av. Padre Cruz, PT-1649-016 Lisbon (Portugal)

E-Mail ana.rito@insa.min-saude.pt or arito@ ceidss.com 


\section{Resumo}

Introdução: Embora sejam reconhecidos os benefícios para a saúde decorrentes da Dieta Mediterrânica (DM), tem-se verificado um decréscimo na adesão a este padrão alimentar, particularmente em idades mais jovens e em regiões Mediterrânicas, Portugal incluído. Estilos de vida e fatores socioeconómicos têm demonstrado influenciar os hábitos alimentares de crianças e adolescentes. Este estudo tem como objetivo analisar a associação entre os fatores socioeconómicos, o estado nutricional e a adesão à DM através do programa Eat Mediterranean. Metodologia: O IMC e a adesão à DM dos participantes foram aferidos no início do programa e após a intervenção do mesmo. Informação relativa ao estatuto socioeconómico e o índice KIDMED foram recolhidos através dum questionário dirigido à família. A intervenção do programa consistiu em diversas sessões de educação alimentar, em 2 municípios da região Centro de Portugal, onde foram abordados os princípios da DM e a sua promoção. 1,772 participantes (do pré-escolar ao ensino secundário) apresentaram os critérios de inclusão no estudo. Resultados: No final do programa, a adesão à DM melhorou significativamente com um aumento de $17.6 \%$ para uma ótima adesão à DM. O consumo diário de alimentos incluídos na DM aumentou também significativamente enquanto o consumo de alimentos de elevada densidade energética diminuiu. O nível de educação da mãe e o rendimento familiar mostraram estar significativamente $(p<0.0001)$ associados a uma ótima adesão à DM pelos participantes em ambas as fases. Entre o estado nutricional e o índice KIDMED não foi encontrada associação. Discussão: O programa Eat Mediterranean demonstrou ser eficaz no aumento da adesão à DM por parte dos participantes uma vez que foi reportada pela maioria dos estudantes no final do programa uma ótima adesão à DM. O rendimento familiar e o nível de educação da mãe foram positivamente associados à qualidade da dieta das crianças e adolescentes participantes.

C 2019 The Author(s). Published by S. Karger AG, Basel on behalf of NOVA National School of Public Health

\section{Introduction}

It has been widely recognized that the Mediterranean diet (MD) represents a complete and nutritionally balanced dietary pattern. Overall, current research has been suggesting an association between a greater adherence to the $\mathrm{MD}$, a reduced risk of mortality, and the incidence of chronic diseases such as cancer, diabetes mellitus type 2, metabolic syndrome, obesity, neuropsychological diseases and cardiovascular diseases, by decreasing its risk factors, resulting in a positive impact on health and quality of life [1-4]. It is originally from the countries surrounding the Mediterranean Basin or that were influenced by it, as it is seen with Portugal [5]. Although there are regional differences, the MD is characterized by a substantial intake of fruits, vegetables, bread and cereals (primarily whole-grain), pulses, nuts, a regular intake of fish, a moderate intake of dairy and a small intake of red meat $[2,6]$. Regardless of the broad evidence concerning the health benefits of this diet, recent data indicate that adherence to this eating pattern is decreasing in the Mediterranean regions, particularly among younger populations [7-9]. In Portugal, this deviation from the Mediterranean pattern is also occurring [10].

Among children and adolescents, epidemiological evidence suggests that dietary patterns in the Mediterranean countries are changing rapidly, with an increased consumption of animal products and saturated fat and a decline in intake of basic vegetable-based foodstuffs [1012]. Recent nutritional surveys carried out in Portugal also suggest that individuals are moving away from the traditional MD towards a Western dietary pattern, mainly in young generations $[13,14]$.

Furthermore, a poor dietary pattern is strongly associated with a higher prevalence of childhood obesity, which has been evidently shown in southern European countries, particularly the Mediterranean ones [12]. Although it seems that childhood obesity has plateaued in Europe in recent years [15], Greece, Italy, Spain, Malta, and Portugal have been consistently the countries with the highest prevalence of childhood overweight and obesity [16]. According to the Childhood Obesity Surveillance Initiative (COSI) in Portugal [17-19], data from the last 10 years have shown a prevalence of overweight above $30 \%$ in children from 6 to 8 years old, of which $11.7 \%$ were obese in 2016. In terms of overweight or obesity prevalence in adolescents, up to $30 \%$ of boys and $21 \%$ of girls among 11-year-olds were overweight, according to the 2014 Health Behavior in School-aged Children (HBSC) survey [20]. Among 13-year-olds, the corresponding figures were $28 \%$ for boys and $24 \%$ for girls, and among 15 -year-olds, 21 and $16 \%$, respectively [20]. The vast literature has demonstrated that children and adolescents' eating habits are strongly influenced by several factors in which socioeconomic and lifestyle factors (parental occupational status, maternal level of education, income) strongly influence eating habits in children and adolescents [21-24]. Children belonging to families that do not 
have adequate resources are more likely to be obese, have a poor dietary pattern, and face a greater burden of illhealth than children who grow up in families that are better off [25]. Addressing these important issues is, therefore, a priority for children.

There is evidence that tracking nutritional behaviours and promoting a change towards a healthier lifestyle from younger ages into adulthood is beneficial and represents great health gains $[11,22]$.

Moreover, adopting the MD principles is simple and achievable as it promotes the consumption of healthy, local, cultural, seasonal, traditionally cooked, and affordable food items [13].

"Eat Mediterranean (EM) - a program for Eliminating Dietary Inequalities in Schools" was developed to address these and other issues, in Portugal, in 2016. EM was a community-based intervention which followed the public health intervention strategy recommended by the World Health Organization (WHO) incorporated in the National Health Plan [26]. The program's goal was to reduce nutritional inequalities in school children through the promotion of the $\mathrm{MD}$, giving priority to the school environment as a means to achieve this goal. The efforts were promoted by the educational community where a network of partnerships aligned in the sectors of health, education, and municipalities. The EM program involved a comprehensive approach both at the individual level child and family, but also at the group/community level (nutritional education sessions at school).

The aim of this study was to assess the children's MD compliance and its association with socioeconomic determinants, as well as participant's nutritional status, before and after the intervention of the EM program.

\section{Methods}

\section{Participants}

The EM program was developed during the 2015/2016 school year (first stage - Diagnosis) to 2016/2017 (second stage - Intervention and Evaluation). The Program targeted 3 Public Schools Groupings with an initial estimated number of 5,773 students in 25 schools (including Preschools, Primary schools and Secondary schools) and 257 classes in Santarém and Alpiarça Municipalities.

From the 5,773 students initially selected and invited to participate, 3,965 children in the first stage and 3,894 in the second stage agreed to be part of the program. For the present study, participants were considered eligible if they met the following criteria: (a) participation in both stages; (b) having valid answers to the 16 items of the Mediterranean Diet Quality Index (KIDMED). This study includes 1,772 children and adolescents from preschool to secondary school (927 girls and 845 boys) aged 2-21 years old (mean age of $11.9 \pm 3.5$ years).

KIDMED Adherence in Portugal -

Eat Mediterranean

\section{Data Collection}

Nutritional Status

Nutritional status was assessed by 20 trained field examiners (of a total of 164 trained Health and Education Professionals), with informed consent given by parents or guardians (letter) and by students (verbal consent), prior to evaluation. Anthropometric measurements (weight and stature) were performed according to a standardized protocol drawn up by EM, based on WHO Guidelines [27]. Anthropometric measurements were carried out in both stages, and the instruments used were calibrated digital scales SECA $^{\circledR} 813$ as well as portable stadiometers SECA ${ }^{\circledR} 217$. Students' weight was measured in kilograms, to the nearest 100-gram unit $(0.1 \mathrm{~kg})$, and stature was measured to the nearest millimeter . Body mass index (BMI) was calculated using the formula weight $(\mathrm{kg}) /$ [height $(\mathrm{m})^{2}$ ], where height was the mean of the two height measurements performed in every child. Nutritional Status of the children and adolescents used the sex-specific BMI-for-age references from WHO 2007 Growth Reference [28] which defines thinness, pre-obesity and obesity as a BMI $\left(\mathrm{kg} / \mathrm{m}^{2}\right)$-for-age $<-2$ standard deviation (SD),$+1<\mathrm{SD}<+2$ (equivalent to a BMI of 25 at 19 years) and $>+2$ SD (equivalent to a BMI of 30 at 19 years), respectively. Above 18 years old, the WHO criteria for adults [29] was considered (thinness: $\mathrm{BMI}<18.5$; overweigh: $\mathrm{BMI} \geq 25$; obesity: BMI $\geq 30$ ).

KIDMED and Socioeconomic Variables

Using the family record form, data regarding parental socioeconomic position and the Mediterranean Diet Quality Index for children and adolescents (KIDMED) were collected in both stages (baseline values were collected in the first stage and post-intervention values in the second).

The KIDMED index has been previously described elsewhere [30] and is based on principles sustaining Mediterranean dietary patterns as well as those that undermine it [30]. The index ranges from 0 to 12 and is based on 16 questions. Questions denoting a negative connotation with respect to the $\mathrm{MD}$ are assigned a value of -1 , and those with a positive aspect, a score of +1 . The sums of the values from the test are classified into three levels: scores $\geq 8$ are considered "optimal MD," 4-7 as "average MD adherence, improvement needed to adjust intake to Mediterranean patterns," and $\leq 3$ as "very low diet quality" [30].

The EM Family questionnaire, which included sociodemographic parameters, was adapted from validated questionnaires, namely the ones used in COSI Portugal study [17] and the HBSC survey [20]. Socioeconomic status was set according to two indicators: maternal educational level and monthly household income level, as these have been the ones most frequently used in association with childhood obesity prevalence studies [21]. Maternal education referred to the highest level of education that had been completed by the child's mother. This variable was regrouped into four answer options: primary school (grade 1-9), secondary school (grade 10-12), undergraduate/Bachelor's degree, and Master's degree or higher. Monthly household income was reported using three income groups: (1) up to EUR 1,500 defined as low income; (2) from EUR 1,500 to 2,500, defined as middle income; and (3) over EUR 2,500, defined as high income.

\section{Intervention Procedures}

The intervention period consisted of nutritional education sessions, divided into 4 themes, towards all students, and held in the 
Table 1. KIDMED questionnaire and KIDMED index in children and adolescents aged 2-21 years old - Eat Mediterranean program, first stage (2015/2016) and second stage (2016/2017)

\begin{tabular}{|c|c|c|c|c|c|c|c|c|}
\hline \multicolumn{4}{|c|}{ First stage } & \multicolumn{4}{|c|}{ Second stage } & \multirow{3}{*}{$\begin{array}{l}\text { McNemar } \\
\text { test } \\
p \text { value }\end{array}$} \\
\hline \multicolumn{2}{|c|}{ no } & \multicolumn{2}{|c|}{ yes } & \multicolumn{2}{|c|}{ no } & \multicolumn{2}{|c|}{ yes } & \\
\hline$n$ & $\%$ & $n$ & $\%$ & $n$ & $\%$ & $n$ & $\%$ & \\
\hline
\end{tabular}

\section{KIDMED questionnaire}

Fruit or juice daily

Second serving of fruit daily

Fresh or cooked vegetables daily

Fresh or cooked vegetables $>1 /$ day

Regular fish consumption (at least 2-3/week)

$>1$ /week fast-food (hamburger) restaurant

Pulses $>1$ /week

Pasta or rice almost daily ( $\geq 5 /$ week)

Regular nut consumption (at least 2-3/week)

Cereal or cereal product for breakfast

Use of olive oil at home

No breakfast

Dairy product for breakfast

Two yoghurts and/or 40 g cheese daily

Commercially baked goods or pastries for breakfast

Sweets and candy several times a day

KIDMED index

Poor $(\leq 3)$

Average (4-7)

Optimal $(\geq 8)$

$\begin{array}{rr}594 & 33.5 \\ 924 & 52.1 \\ 64 & 3.6 \\ 663 & 5.6 \\ 264 & 14.9 \\ 1,293 & 73.0 \\ 607 & 34.3 \\ 221 & 12.5 \\ 1,500 & 84.7 \\ 601 & 33.9 \\ 92 & 5.2 \\ 1,717 & 96.9 \\ 125 & 7.1 \\ 819 & 46.2 \\ 1,658 & 93.6 \\ 1,484 & 83.7\end{array}$

\begin{tabular}{rr}
1,178 & 66.5 \\
848 & 47.9 \\
1,708 & 96.4 \\
11,093 & 94.4 \\
1,508 & 85.1 \\
479 & 27.0 \\
1,165 & 65.7 \\
1,551 & 87.5 \\
272 & 15.3 \\
1,171 & 66.1 \\
1,680 & 94.8 \\
55 & 3.1 \\
1,647 & 92.9 \\
953 & 53.8 \\
114 & 6.4 \\
288 & 16.3 \\
\hline
\end{tabular}

$\begin{array}{rr}585 & 33.0 \\ 851 & 48.0 \\ 10 & 0.6 \\ 124 & 7.0 \\ 215 & 12.1 \\ 1,278 & 72.1 \\ 482 & 27.2 \\ 227 & 12.8 \\ 1,336 & 75.4 \\ 179 & 10.1 \\ 23 & 1.3 \\ 1,720 & 97.1 \\ 147 & 8.3 \\ 766 & 43.2 \\ 1,714 & 96.7 \\ 1,621 & 91.5\end{array}$

1,187
921
1,762
1,648
1,557
494
1,290
1,545
436
1,593
1,749
52
1,625
1,006
58
151

$\begin{array}{ll}67 & 0.719\end{array}$

$52 \quad 0.001$

$99<0.0001$

$93<0.0001$

$88 \quad 0.003$

$\begin{array}{ll}28 & 0.539\end{array}$

0.539
$<0.0001$

0.753

$<0.0001$

$<0.0001$

$<0.0001$

0.824

0.124

0.042

$<0.0001$

$<0.0001$

$\begin{array}{cc}33(1.9 \%) & 8(0.5 \%) \\ 704(39.7 \%) & 417(23.5 \%) \\ 1,035(58.4 \%) & 1,347(76.0 \%)\end{array}$

$<0.0001$ classrooms. The content of these thematic sessions was previously prepared, discussed, and translated into practical sessions by the scientific group and by all nutritionists ( 9 in total) involved in the project. A very well-described session guide/manual was produced in order for the trained nutritionists to apply the same methodology with the same educational materials according to the education level for which these had been prepared. The sessions took place in the period between February and October 2016, except for grade 12 students who finished high school in June 2016. In order to be possible to address all 4 themes, the sessions had to be adjusted according to the school schedule and teachers' availability. In total, 971 sessions of 45-50 min each were carried out, and 190 teachers as well as 257 classes were involved. Teachers had an important role in the planning of the sessions by helping the nutritionists from the EM program to adjust the sessions' content and approach to the students' different education levels (from preschool to secondary). The different thematic sessions focused on the topic of "Breakfast" (the first), the second was about "Morning and afternoon snacks," the third was about "Soup" and the last focused on a "Mediterranean day." Following the descriptive session guide/manual step-by-step procedures, the methodology followed was based on the active involvement and empowerment of every student by encouraging their participation and allowing them to be the main actors of the intervention. All sessions included the theoretical/educational part; application of education materials (cooking workshops, taste tests, games, activity sheets, and other ludic materials) encouraging the development of students' skills and behaviours, and quizzes or simple questionnaires to assess the impact of the session (acquiring knowledge, attitude regarding each theme).

The first session focused on the topic of "Breakfast," addressing the composition of a nutritionally balanced and healthy first and important meal of the day. The second session theme "Morning and afternoon snacks" reinforced the importance of being an autonomous child/adolescent in making better food choices for healthy, practical, and affordable snacks. The session regarding "Soup" explored the benefits of including a vegetable soup in the everyday eating habits. The children and adolescents were invited to prepare a soup in the classroom and taste it. In the last session, entitled "Mediterranean day," all the previous themes were revised and reinforced with additional promotion of healthy lifestyle activities related to the "Mediterranean food wheel." These included an emphasis on the MD concept and principles promoting a valuable and balanced lifestyle with a diverse dietary pattern which promotes tradition, costumes, and celebrates conviviality around the table as well as other aspects such as the promotion of higher levels of physical activity and sleep.

\section{Statistical Analysis}

Analysis was performed using the SPSS statistical software package version 24.0 (SPSS Inc., Chicago, IL, USA). To determine the differences between the answers of the KIDMED test in the two stages, the McNemar test was used. To evaluate the participants' KIDMED index according to gender, age groups, mother's educa- 
Table 2. KIDMED index in children and adolescents by gender, age, mother's educational level and gross income of the household - Eat Mediterranean program, first stage (2015/2016) and second stage $(2016 / 2017)$

\begin{tabular}{|c|c|c|c|c|c|c|c|c|}
\hline & \multicolumn{4}{|l|}{ First stage } & \multicolumn{4}{|c|}{ Second stage } \\
\hline & $\begin{array}{l}\text { poor } \\
(\leq 3)\end{array}$ & $\begin{array}{l}\text { medium } \\
(4-7)\end{array}$ & $\begin{array}{l}\text { optimal } \\
(\geq 8)\end{array}$ & $p$ value & $\begin{array}{l}\text { poor } \\
(\leq 3)\end{array}$ & $\begin{array}{l}\text { medium } \\
(4-7)\end{array}$ & $\begin{array}{l}\text { optimal } \\
(\geq 8)\end{array}$ & $p$ value \\
\hline \multicolumn{9}{|l|}{ Gender } \\
\hline Male $(n=845)$ & $16(1.9 \%)$ & $337(39.9 \%)$ & $492(59.2 \%)$ & 0.986 & $6(0.7 \%)$ & $208(24.6 \%)$ & $631(74.7 \%)$ & 0.167 \\
\hline \multicolumn{9}{|l|}{ Age group } \\
\hline $2-5(n=61)$ & $1(1.6 \%)$ & $24(39.3 \%)$ & $36(59.0 \%)$ & $<0.0001$ & $1(1.6 \%)$ & $16(26.2 \%)$ & $44(72.1 \%)$ & 0.006 \\
\hline $6-9(n=402)$ & $5(1.2 \%)$ & $120(29.9 \%)$ & $277(68.9 \%)$ & & $1(0.2 \%)$ & $70(17.4 \%)$ & $331(82.3 \%)$ & \\
\hline $10-14(n=805)$ & $11(1.4 \%)$ & $304(37.8 \%)$ & $490(60.9 \%)$ & & $2(0.2 \%)$ & $192(23.9 \%)$ & $611(75.9 \%)$ & \\
\hline$\geq 15(n=504)$ & $16(3.2 \%)$ & $256(50.8 \%)$ & $232(46.0 \%)$ & & $4(0.8 \%)$ & $139(27.6 \%)$ & $361(71.6 \%)$ & \\
\hline \multicolumn{9}{|l|}{ Mother's educational level ${ }^{\mathrm{a}}$} \\
\hline \multicolumn{9}{|l|}{ Monthly income of the household ${ }^{\mathrm{b}}$} \\
\hline $0-1,500(n=786)$ & $16(2.0 \%)$ & $344(43.8 \%)$ & $426(54.2 \%)$ & $<0.0001$ & $4(0.5 \%)$ & $213(27.1 \%)$ & $569(72.4 \%)$ & $<0.0001$ \\
\hline $1,500-2,500(n=394)$ & $4(1.0 \%)$ & $128(32.5 \%)$ & $262(66.5 \%)$ & & $2(0.5 \%)$ & $66(16.8 \%)$ & $326(82.7 \%)$ & \\
\hline $2,500-3,000(n=227)$ & $1(0.4 \%)$ & $73(32.2 \%)$ & $153(67.4 \%)$ & & $0(0.0 \%)$ & $42(18.5 \%)$ & $185(81.5 \%)$ & \\
\hline
\end{tabular}

a $n=1,413$, due to missing value. ${ }^{\mathrm{b}} n=1,407$, due to missing values.

tional level, monthly income of the household, and nutritional status, the $\chi^{2}$ test was used. Differences were considered statistically significant when $p<0.05$.

\section{Results}

Table 1 shows the results of children and adolescents' MD adherence (KIDMED) in the first and second stage of the EM program.

Between the two stages there was a significant decrease in the proportion of students who had a low diet quality from $1.9 \%$ in the first stage to $0.5 \%$ in the second $(p<$ $0.0001)$. A decrease was also observed in the category of average MD adherence, where the proportion was 39.7\% in the first stage and changed to $23.5 \%$ in the second, resulting in a difference of $-16.2 \%$. Regarding the proportion of students with an optimal MD, an increase of $17.6 \%$ from the first stage $(58.4 \%)$ to the second $(76.0 \%)$, was observed. The differences in the KIDMED index between the two stages were statistically significant $(p<0.0001)$.

With regard to the answers given in both stages to each question of the KIDMED test, a significant increase in intake was found, from stage 1 to stage 2 , concerning the "intake of a second serving of fruit daily" $(p=0.001)$, the "daily intake of fresh or cooked vegetables" ( $p<0.0001)$, "regular fish consumption" ( $p<0.003)$, the "intake of pulses and nuts" $(p<0.0001)$, the "intake of cereals or cereal products" ( $p<0.0001)$, and the "daily intake of dairy, namely yoghurts and cheese" $(p=0.042)$. A decrease in the intake of "commercially baked goods or pastries for breakfast" and of "sweets and candy" was observed with statistically significant differences $(p<0.0001)$ between the two stages.

Tables 2 and 3 reflect the influence of sex, age, mother's educational level, monthly income of the household and nutritional status on the MD index. There were no significant differences between sex and MD index. In contrast, significant differences were observed between the four age groups and the KIDMED index. In both stages, 6- to 9-year-old children presented the most positive values as $68.9 \%$ of the participants in the first stage and $82.3 \%$ in the second stage showed to have an optimal MD. The lowest adherence to optimal diet was found in adolescents and older participants (15-21 years old) in the first stage (46.0\%); nevertheless, this group almost dou- 
Table 3. KIDMED index in children and adolescents by nutritional status - Eat Mediterranean program, first stage (2015/2016) and second stage (2016/2017)

\begin{tabular}{|c|c|c|c|c|}
\hline \multirow[t]{2}{*}{ Nutritional status } & \multicolumn{4}{|c|}{ KIDMED index } \\
\hline & poor $(\leq 3)$ & medium $(4-7)$ & optimal $(\geq 8)$ & $p$ value \\
\hline \multicolumn{5}{|l|}{ First stage } \\
\hline Thinness $(n=20 / 1.1 \%)$ & $2(10.0 \%)$ & $7(35.0 \%)$ & $11(55.0 \%)$ & 0.088 \\
\hline Normal weight $(n=1,187 / 67.0 \%)$ & $22(1.8 \%)$ & $485(40.9 \%)$ & $680(57.3 \%)$ & \\
\hline Pre-obesity $(n=376 / 21.2 \%)$ & $5(1.3 \%)$ & $131(34.8 \%)$ & $240(63.9 \%)$ & \\
\hline Obesity $(n=189 / 10.7 \%)$ & $4(2.1 \%)$ & $81(42.9 \%)$ & $104(55.0 \%)$ & \\
\hline \multicolumn{5}{|l|}{ Second stage } \\
\hline Thinness $(n=21 / 1.2 \%)$ & $0(0.0 \%)$ & $3(14.3 \%)$ & $18(85.7 \%)$ & 0.001 \\
\hline Normal weight $(n=1,234 / 69.6 \%)$ & $6(0.5 \%)$ & $329(26.7 \%)$ & $899(72.8 \%)$ & \\
\hline Pre-obesity $(n=357 / 20.1 \%)$ & $1(0.3 \%)$ & $59(16.5 \%)$ & $297(83.2 \%)$ & \\
\hline Obesity $(n=160 / 9.0 \%)$ & $1(0.6 \%)$ & $26(16.3 \%)$ & $133(83.1 \%)$ & \\
\hline
\end{tabular}

bled (71.6\%) their MD adherence from the first stage to the second.

As for socioeconomic variables and the MD index, mother's educational level was positively and significantly $(p<0.0001)$ associated with optimal MD adherence by children and adolescent, in both stages. Children and adolescents whose mothers had higher educational levels (undergraduate or higher) showed a higher KIDMEX index.

Similarly, regarding income of the household, the percentage of the participants with an optimal MD (>66\% first stage, $>81 \%$ second stage) was higher in the categories of higher income (EUR >1,501/month) versus 54.2\% (first stage) and $72.4 \%$ (second stage) in the lower income group $(<$ EUR 1,500$)$.

According to Table 3, no significant variation between participants' nutritional status and MD adherence was seen in the first stage. From stage 1 to stage 2, the prevalence of obesity (from 10.7 to $9.0 \%$ ) and pre-obesity (from 21.2 to $20.1 \%$ ) decreased, increasing the proportion of individuals in the normal weight category from 67 to $69.6 \%$. All of the categories of nutritional status improved their adherence to MD from stage 1 (from 55 to $63.9 \%$ ) to stage 2 (from 72.8 to $85.7 \%$ ).

\section{Discussion}

Since countries around the Mediterranean basin have consistently shown higher overweight and obesity prevalence in children, the promotion of healthy lifestyles using the MD principles has increased in popularity among the scientific community [31]. In previous studies, the ad- herence to the MD using KIDMED has shown poor results among children and adolescents [8, 32], reinforcing the need to intervene in these age groups.

At baseline of the EM program, KIDMED index results showed that only about half of the participants had "optimal MD" (58.4\%) adherence. Similar findings were shown by Portuguese colleagues in children aged 11-16 years from Algarve, where 52.5\% also had an "optimal MD” KIDMED index [13].

Successful results were achieved after the intervention and implementation of the EM program. There was a $17.6 \%$ increase in the adherence to an optimal MD, meaning that 312 children improved their dietary habits, over a period of 1 year. According to the KIDMED test, the significant increase in the intake of fruit, vegetables, fish, pulses, nuts, cereals or cereal products, and dairy led to the improvement of the diet quality from the first stage to the second. On the other hand, the significant decrease in the intake of commercially baked goods or pastries and of sweets and candy also contributed to the high proportion of participants with an optimal diet quality, suggesting that the program was well received, and the format and messages incorporated in the nutrition education session were well perceived.

Comparing the results of "optimal MD" adherence obtained in these Portuguese studies with additional studies from other southern European countries, some differences can be noted. Except for Spain where children and adolescents showed an "optimal MD" adherence of over 40\% [30], studies from Turkey (age 12-14 years: 22.9\%) [6], Italy (mean age 16.8 years: 16.5\%) [32], Cyprus (mean age 10.7 years: 6.7\%) [33], and Greece showed lower rates of MD adherence for this category. In fact, the Greek 
study conducted at the national level showed that only $4.3 \%$ of the children had an optimal KIDMED score, while nearly half were classified as having a "very low diet quality" (46.8\%) [8]. Findings from the "Identification and Prevention of Dietary- and Lifestyle-Induced Health Effects in Children and Infants (IDEFICS)" study, conducted not only in Southern Europe (Italy, Spain and Cyprus) but also in Northern (Sweden and Estonia) and Central Europe (Hungary, Belgium, and Germany), supported that a Mediterranean-like dietary pattern is not necessarily a feature of the Mediterranean countries since children from Southern European countries, except from Italy, showed even lower adherence than their peers living in Central and Northern European countries [34, 35].

As previously stated, parental educational level and socioeconomic status have an effect on children and adolescents' dietary habits. Results of this study showed a positive association with statistical significance between the mother's educational level and the KIDMED index, showing that a higher KIDMED index was linked to higher educational levels. Similar findings in previous studies conducted in countries such as Spain $[11,30]$ and Turkey [6] also showed that a predictor of adherence to the MD was the mother's education. Regarding the socioeconomic aspect, our results support the findings of previous Spanish studies $[11,22,30]$ since the proportion of participants with medium-to-high incomes that reported an optimal MD was greater than the proportion amongst individuals with low incomes. Also, in Italy, particularly in the southern region, one of the major predictors of high adherence to Mediterranean dietary pattern was high socioeconomic status [36]. On the other hand, findings from the IDEFICS study showed that generally higher adherence to the MD was associated with higher income but not consistently across countries, as income was not determinant in Sweden [34, 35], suggesting that in southern European countries socioeconomic factors are major determinants of adherence to the MD but not in all European countries.

In agreement with findings from other countries, namely Spain $[22,30]$ and Turkey [6], no statistically significant differences between sex and the KIDMED index were observed in this study.

Although no statistically significant association was found between an impaired nutritional status, according to BMI, and the KIDMED index, the vast literature has shown that low parental education, particularly maternal education, is associated with children's malnutrition [21]. This combined with low socioeconomic status represents a challenge to be addressed.

KIDMED Adherence in Portugal Eat Mediterranean
Clearly, this program that promoted on continuous ground a healthy lifestyle pattern in children and adolescents, improved the nutritional status of the participants. EM proved to have a positive effect on the participants overweight prevalence, since from stage 1 to stage 2 , the prevalence of obesity and pre-obesity decreased from 10.7 to $9.0 \%$ and from 21.2 to $20.1 \%$, respectively. Moreover, all of the categories of nutritional status improved their adherence to MD over the EM program period.

Additionally, as for the association between malnutrition and the KIDMED index, controversial results have been found in the literature. While some studies observed an inverse association between the Mediterranean dietary pattern and BMI $[33,37,38]$, others found no relationship between BMI and the KIDMED index [8].

It is important to point out that this study is based on a program that consisted of a very intensive and comprehensive nutritional intervention, and at the end of it there was an improvement not only in the nutritional status of the participants but also in the overall dietary habits and, therefore, closer to the MD pattern.

\section{Conclusion}

The results in this study indicate that there was a positive effect on the adherence to the MD since $76.0 \%$ of the participants reported an optimal MD at the end of the EM program.

Factors such as higher socioeconomic status and mother's educational level had a positive impact on the diet quality of the children and adolescents; however, a relationship between other factors, namely the nutritional status and the KIDMED index was not observed, but as the literature has shown controversial results, more research is needed on this issue.

The EM program proved to be successful in changing the children's and adolescents' dietary patterns, supporting that comprehensive school-based nutritional programs can be an effective policy measure towards a healthier living among children and adolescents.

\section{Acknowledgements}

The authors wish to acknowledge all the nutritionists, psychologists and other health professionals, children, parents, educators, teachers, school cooking staff, and municipality technicians for their contribution to the field work, as well as the following Institutions for their partnership and support: Agrupamentos de Escolas Dr. Ginestal Machado, Sá da Bandeira e de José Relvas; Hospi- 
tal Distrital de Santarém; CEIDSS - Centro de Estudos e Investigação em Dinâmicas Sociais e Saúde; ISCTEIUL - Instituto Universitário de Lisboa; Municipalities of Alpiarça and Santarém and Instituto Nacional de Saúde Doutor Ricardo Jorge.

\section{Statement of Ethics}

Ethical approval for this study was obtained from the Regional Health Administration of Lisbon and Tagus Valley Ethics Committee.

\section{Disclosure Statement}

The authors declare that they have no conflicts of interest.

\section{Funding Sources}

The EM program (2015-2017) was coordinated by ARSLVT, Portugal, co-funded by the Public Health Initiatives Program (PT06) of the EEA Grants, to the grant application 171NU2.

\section{Author Contributions}

The authors' contributions are as follows: A.I.R. was part of the coordinating team of Eat Mediterranean and worked in all stages of the research, such as project design, analysis and interpretation of the data, and writing of the manuscript; A.D., A.M., C.R., coordinated and implemented the Eat Mediterranean program, working on the project design, data collection, and interpretation of the data; all authors helped in the revision of final text and approved the final version of the manuscript.

\section{References}

1 Trichopoulou A, Bamia C, Trichopoulos D. Anatomy of health effects of Mediterranean diet: Greek EPIC prospective cohort study. BMJ. 2009 Jun;338:b2337.

2 Serra-Majem L, Trichopoulou A, Ngo de la Cruz J, Cervera P, García Alvarez A, La Vecchia C, et al.; International Task Force on the Mediterranean Diet. Does the definition of the Mediterranean diet need to be updated? Public Health Nutr. 2004 Oct;7(7):927-9.

3 Sofi F, Abbate R, Gensini GF, Casini A. Accruing evidence on benefits of adherence to the Mediterranean diet on health: an updated systematic review and meta-analysis. Am J Clin Nutr. 2010 Nov;92(5):1189-96.

4 Romaguera D, Norat T, Vergnaud AC, Mouw T, May AM, Agudo A, et al. Mediterranean dietary patterns and prospective weight change in participants of the EPIC-PANACEA project. Am J Clin Nutr. 2010 Oct;92(4): 912-21.

5 Durão CR, Oliveira JF, de Almeida MD. Portugal e o padrão alimentar mediterrânico. Rev Aliment Hum. 2008;14(3):115-28.

6 Sahingoz SA, Sanlier N. Compliance with Mediterranean Diet Quality Index (KIDMED) and nutrition knowledge levels in adolescents. A case study from Turkey. Appetite. 2011 Aug;57(1):272-7.

7 García Cabrera S, Herrera Fernández N, Rodríguez Hernández C, Nissensohn M, Román-Viñas B, Serra-Majem L. KIDMED test; prevalence of low adherence to the Mediterranean Diet in children and young: a systematic review. Nutr Hosp. 2015 Dec;32(6): 2390-9.

8 Farajian P, Risvas G, Karasouli K, Pounis GD, Kastorini CM, Panagiotakos DB, et al. Very high childhood obesity prevalence and low adherence rates to the Mediterranean diet in Greek children: the GRECO study. Atherosclerosis. 2011 Aug;217(2):525-30.
9 Hebestreit A, Ahrens W. Relationship between dietary behaviours and obesity in European children. Int J Pediatr Obes. 2010; Suppl 1:45-7.

10 Rodrigues SS, Caraher M, Trichopoulou A, de Almeida MD. Portuguese households' diet quality (adherence to Mediterranean food pattern and compliance with WHO population dietary goals): trends, regional disparities and socioeconomic determinants. Eur J Clin Nutr. 2008 Nov;62(11):1263-72.

11 Bibiloni MM, Martínez E, Llull R, Pons A, Tur JA. Western and Mediterranean dietary patterns among Balearic Islands' adolescents: socio-economic and lifestyle determinants. Public Health Nutr. 2012 Apr;15(4):683-92.

12 Börnhorst $C$, Wijnhoven TM, Kunešová $M$, Yngve A, Rito AI, Lissner L, et al. WHO European Childhood Obesity Surveillance Initiative: associations between sleep duration, screen time and food consumption frequencies. BMC Public Health. 2015 Apr;15(1):442.

13 Mateus MP, Graça P. Adesão ao padrão alimentar mediterrânico em jovens no Algarve. Doutoramento em Ciências do Consumo Alimentar e Nutrição. Porto: Universidade do Porto; 2014 [accessed 2017 Dec 21]. Avaible from: http://hdl.handle.net/10216/66678.

14 Lopes C, Torres D, Oliveira A, Severo M, Alarcão V, Guiomar S, et al. Inquérito Alimentar Nacional e de Atividade Física: IANAF 2015-2016. Porto: Universidade do Porto; 2017 [accessed 2017 Feb 15]. Available from: https://ian-af.up.pt/resultados.

15 Abarca-Gómez L, Abdeen Z, Hamid Z, AbuRmeileh N, Acosta-Cazares B, Acuin C, et al.; NCD Risk Factor Collaboration (NCD-RisC). Worldwide trends in body-mass index, underweight, overweight, and obesity from 1975 to 2016: a pooled analysis of 2416 populationbased measurement studies in 128.9 million children, adolescents, and adults. Lancet. 2017 Dec;390(10113):2627-42.
16 Wijnhoven TM, van Raaij JM, Spinelli A, Starc G, Hassapidou M, Spiroski I, et al. WHO European Childhood Obesity Surveillance Initiative: body mass index and level of overweight among 6-9-year-old children from school year 2007/2008 to school year 2009/2010. BMC Public Health. 2014 Aug; 14(1):806.

17 Rito AI, Cruz de Sousa R, Mendes S, Graça P. Childhood Obesity Surveillance Initiative: COSI Portugal 2016. Lisbon: Instituto Nacional de Saúde Dr. Ricardo Jorge; 2017 [accessed 2017 Dec 15]. Available from: http:// hdl.handle.net/10400.18/4857.

18 Rito AI, Graça P. Childhood Obesity Surveillance Initiative: COSI Portugal 2013. Lisbon: Instituto Nacional de Saúde Dr. Ricardo Jorge; 2015 [accessed 2017 Nov 15]. Available from: http://hdl.handle.net/10400.18/3108.

19 Rito AI, Paixão E, Carvalho MA, Ramos C. Childhood Obesity Surveillance Initiative COSI Portugal 2008. Lisbon: Instituto Nacional de Saúde Dr. Ricardo Jorge; 2011 [accessed 2017 Oct 15]. Available from: http:// hdl.handle.net/10400.18/142.

20 World Health Organization. Regional Office for Europe. Growing up unequal: gender and socioeconomic differences in young people's health and well-being: Health Behaviour in School-Aged Children (HBSC) Study: international report from the 2013/2014 survey. Copenhagen: World Health Organization; 2016 [accessed 2017 Dec 05]. Available from: http://www.euro.who.int/_data/assets/pdf_ file/0003/303438/HSBC-No.7-Growing-upunequal-Full-Report.pdf?ua $=1$

21 Lissner L, Wijnhoven TM, Mehlig K, Sjöberg A, Kunesova M, Yngve A, et al. Socioeconomic inequalities in childhood overweight: heterogeneity across five countries in the WHO European Childhood Obesity Surveillance Initiative (COSI-2008). Int J Obes. 2016 May; 40(5):796-802. 
22 Arriscado D, Muros JJ, Zabala M, Dalmau JM. Factors associated with low adherence to a Mediterranean diet in healthy children in northern Spain. Appetite. 2014 Sep;80:28-34.

23 Taylor JP, Evers S, Mckenna M. Determinants of healthy eating in children and youth. Can J Public Health 2005 Jul-Aug; 96 Suppl 3:S20-6, S22-9.

24 Fauquet J, Sofi F, López-Guimerà G, Leiva D, Shalà $\mathrm{A}$, Puntí J, et al. Mediterranean diet adherence among Catalonian adolescents: socio-economic and lifestyle factors. Nutr Hosp. 2016 Nov;33(6): 1283-90.

25 Barnes S. Reducing childhood obesity in Ontario through a health equity lens. Toronto: Wellesley Institute. 2012 [accessed 2017 Dec 22]. Available from: http://www.wellesleyinstitute.com/publications/reducing-childhood-obesity-in-ontario-through-a-healthequity-lens/.

26 Direção-Geral da Saúde, Ministério da Saúde, Portugal. Plano Nacional de Saúde: revisão e extensão a 2020. Lisbon: Direcção Geral da Saúde; 2015 [accessed 2017 Nov 12]. Available from: http://pns.dgs.pt/files/2015/06/ Plano-Nacional-de-Saude-Revisao-e-Extensao-a-2020.pdf.pdf.

27 World Health Organization. Childhood Obesity Surveillance Initiative (COSI): data collectin procedures. Copenhagen: World Health Organization; 2016 [accessed 2017 Jun
12]. Available from: http://www.euro.who. int/en/health-topics/disease-prevention/nutrition/publications/2017/childhood-obesity-surveillance-initiative-cosi-data-collection-procedures-2016.

28 Rito A, Wijnhoven TM, Rutter H, Carvalho MA, Paixão E, Ramos C, et al. Prevalence of obesity among Portuguese children (6-8 years old) using three definition criteria: COSI Portugal, 2008. Pediatr Obes. 2012 Dec;7(6):413-22.

29 World Health Organization. Global Database on Body Mass Index. Copenhagen: World Health Organization; 2004 [accessed 2017 Oct 02]. Available from: http://www.who.int/ nutrition/databases/en/.

30 Serra-Majem L, Ribas L, Ngo J, Ortega RM, García A, Pérez-Rodrigo C, et al. Food, youth and the Mediterranean diet in Spain. Development of KIDMED, Mediterranean Diet Quality Index in children and adolescents. Public Health Nutr. 2004 Oct;7(7):931-5.

31 Pereira-da-Silva L, Rêgo C, Pietrobelli A. The diet of preschool children in the Mediterranean countries of the European Union: a systematic review. Int $J$ Environ Res Public Health. 2016 Jun;13(6):572.

32 Santomauro F, Lorini C, Tanini T, Indiani L, Lastrucci V, Comodo N, et al. Adherence to Mediterranean diet in a sample of Tuscan adolescents. Nutrition. 2014 Nov-Dec;30(1112):1379-83
33 Lazarou C, Panagiotakos DB, Matalas AL. Physical activity mediates the protective effect of the Mediterranean diet on children's obesity status: the CYKIDS study. Nutrition. 2010 Jan;26(1):61-7.

34 Tognon G, Moreno LA, Mouratidou T, Veidebaum T, Molnár $\mathrm{D}$, Russo $\mathrm{P}$, et al.; IDEFICS consortium. Adherence to a Mediterranean-like dietary pattern in children from eight European countries. The IDEFICS study. Int J Obes. 2014 Sep;38(S2 Suppl 2):S108-14.

35 Grosso G, Galvano F. Mediterranean diet adherence in children and adolescents in southern European countries. NFS J. 2016;3:13-9.

36 Grosso G, Marventano S, Buscemi S, Scuderi A, Matalone M, Platania A, et al. Factors associated with adherence to the Mediterranean diet among adolescents living in Sicily, Southern Italy. Nutrients. 2013 Dec;5(12): 4908-23.

37 Tsartsali PK, Thompson JL, Jago R. Increased knowledge predicts greater adherence to the Mediterranean diet in Greek adolescents. Public Health Nutr. 2009 Feb;12(2):208-13.

38 Kontogianni MD, Vidra N, Farmaki AE, Koinaki S, Belogianni K, Sofrona S, et al. Adherence rates to the Mediterranean diet are low in a representative sample of Greek children and adolescents. J Nutr. 2008 Oct; 138(10):1951-6. 